\title{
Detecting the Non-physiological, Surgically Tailored Ileocolic Anastomosis Using the Wireless Motility Capsule. A Pre- and Post-operative, Prospective, Within Subject Trial
}

\author{
Yngve Thorsen, ${ }^{1,2 *}$ Bojan V Stimec, ${ }^{3}$ Jens M Nesgaard, ${ }^{4}$ and Dejan Ignjatovic ${ }^{1,2}$ \\ ${ }^{I}$ Department of Digestive Surgery, Akershus University Hospital, Lorenskog, Norway; ${ }^{2}$ Institute of Clinical Medicine, University of Oslo, Norway; \\ ${ }^{3}$ Faculty of Medicine, Department of Cellular Physiology and Metabolism, Anatomy Sector, University of Geneva, Switzerland; and ${ }^{4}$ Department \\ of Gastrointestinal Surgery, Vestfold Hospital Trust, Tonsberg, Norway
}

\section{Background/Aims}

Wireless motility capsule (WMC) detects the ileocolic junction (ICJ) in most non-operated patients. We find no data concerning this examination in patients where the ileocolic valve is replaced by a per definition incompetent, surgically created ICJ. We wanted to see if WMC could detect the ICJ after a right colectomy and assess the competency.

\section{Methods}

Prospective cohort study using a within-subject design to eliminate subject-subject variability. Selected patients operated with right colectomy underwent 3 WMC examinations (pre-operatively, 3 weeks, and 6 months after surgery).

\section{Results}

Twenty patients (8 men) included, 7 (4 men) excluded due to poor recordings (4) and unforeseen events (3). Thirteen patients (4 men), median age 63 years completed 3 tests. Median bowel lengths removed were $11 \mathrm{~cm}$ for ileum and $21 \mathrm{~cm}$ for colon. Thirty-nine examinations analyzed by 2 physicians who found all $13 \mathrm{ICJ}$ at 3 examinations with high inter-rater reliability (intra-class correlation coefficient: $0.99,0.91$, and 0.99 respectively), whereas the computer found 9,8 , and 10 out of the $13 \mathrm{ICJ}$, respectively. Computed values significantly more often deviated from the 2 raters. Mean magnitude and duration of $\mathrm{pH}$-drop at the ICJ (3 examinations) was 1.16-1.02-1.13 pH units and 3.15-4.78-3.75 minutes, respectively. pH-drop was smaller and duration longer at 3 weeks. We found no differences between the pre-operative (competent ICJ) and post-operative 6-month examinations (incompetent ICJ). Highest pressure immediately prior to ICJ was equal before and after surgery.

\section{Conclusion}

WMC can identify the non-physiological ICJ after right colectomy. lleocolic competence cannot be assessed.

(J Neurogastroenterol Motil 2017;23:585-591)

Key Words

Anastomosis, surgical; Colectomy; Gastrointestinal motility; Gastrointestinal transit; lleocolic valve

Received: November 5, 2016 Revised: January 31, 2017 Accepted: March 12, 2017

(.) This is an Open Access article distributed under the terms of the Creative Commons Attribution Non-Commercial License (http://creativecommons. org/licenses/by-nc/4.0) which permits unrestricted non-commercial use, distribution, and reproduction in any medium, provided the original work is properly cited.

*Correspondence: Yngve Thorsen, MD

Department of Digestive Surgery, Akershus University Hospital, University of Oslo, Norway Tel: +47-67969794, Fax: +47-67969040, E-mail: yngve.thorsen@gmail.com 


\section{Introduction}

Dealing with patients suffering from motility disorders is challenging. Assessment of regional and whole gut transit times can give the information needed for a correct therapeutic approach. ${ }^{1}$ A body of evidence has been built in the literature on the validity of motility monitoring using the SmartPill wireless motility capsule (WMC). ${ }^{2-4}$ The pill measures both whole gut and segmental (stomach, small bowel, and colon) transit times. Segmental transit times are defined as time intervals between important landmarks (pylorus and ileocolic junction [ICJ]) when the capsule moves from one bowel segment to another. Up to now, the WMC has mostly been applied in studies dealing with patients with functional disturbances in an otherwise intact digestive tube. A few patients who had undergone bowel resections were included by Arora et $\mathrm{al}^{5}$ but the precise localization of the bowel segment removed was not defined. Surgeons remove segments of bowel and suture them together in order to maintain bowel continuity. It is, however, not the same if an intestinal landmark (eg, ICJ) or a segment of bowel between these landmarks is removed. Unfortunately, no data can be found in the literature on patients where one or more of these landmarks has been surgically removed and an anastomosis created. The surgically created ICJ is per definition incompetent. Through the years, many authors have described possible consequences of having an incompetent ileocolic valve without having a proper way to assess competence. Roland et $\mathrm{al}^{6}$ suggest that a low pressure prior to the ileocolic valve (defined as highest pressure over a 4-minute window prior to the characteristic ileocecal $\mathrm{pH}$ drop) indicates that the valve is incompetent.

The aim of this study is to demonstrate the capacity of the WMC to locate a surgically created (non-physiologic) ICJ after right colectomy for cancer. A secondary aim is to investigate if competence of the ICJ can be assessed by measuring the pressure prior to the ICJ.

\section{Materials and Methods}

\section{Patients}

Patients in this study were included simultaneously in 2 trials, the "Safe Radical D3 Right Hemicolectomy for Cancer through Pre-operative Biphasic Multi-detector Computed Tomography (MDCT)” (Regional ethics committee Sør-Øst no. 2010/3354), registered at ClinicalTrials.gov on May 9th 2011 (http://clinicaltri-
als.gov/ct2/show/NCT01351714), and the "Comparison of bowel function between D2 and D3 operated patients for right-sided colon cancer" trial (Regional ethics committee sør- $\varnothing$ st no. 2013/206). Participation was voluntary; informed consent forms were signed.

\section{Inclusion Criteria}

Patients under 75 years of age with right-sided colon cancer planned to be operated on with the intent to cure.

\section{Exclusion Criteria}

Patients excluded were those with denied participation, obstructing tumor, post-operative complications, inflammatory bowel disease, known motility disorders, previously performed bowel resections, extended bowel resection, conditions causing motility disorders (celiac disease, diabetes mellitus, scleroderma, Parkinson's disease, and rheumatic conditions), and those using medication that can influence bowel motility.

\section{Study Design}

Data collection was prospective. To eliminate subject-subject variability, a within-subject design was used, rendering patients as their own controls. Selected patients planned for operation with right colectomy with extended D3 mesenterectomy (removal of $10-15 \mathrm{~cm}$ of the terminal ileum, the ascending and proximal transverse colon with an extended D3 mesenterectomy as previously described $^{7,8}$ ) underwent three WMC examinations (pre-operatively, 3 weeks after and 6 months after surgery).

\section{Instruments}

The WMC is an ambulatory non-invasive and non-radioactive diagnostic sensor that continuously measures $\mathrm{pH}$, temperature, and pressure as it passes through the gastrointestinal (GI) tract. ${ }^{9,10}$ The sensor transfers data to a receiver that must be in the patient's proximity.

\section{Testing}

Patients were required to ingest a standard meal (SmartBar a cereal bar, containing $260 \mathrm{kcal}$ ) after 8 hours of fasting and immediately afterward swallow the WMC. After swallowing the capsule, they were asked to refrain from eating for 6 hours. Patients were instructed to wear the receiver as close to the abdomen as possible except while bathing and showering. Furthermore, they were asked to record all bowel movements and meals by pressing the receiver's event button as well as writing down the time displayed together with a brief description of the event/activity in a diary. The patients 
were instructed to wait 3 minutes in the bathroom before flushing the toilet after each bowel movement to ensure that the receiver captured the fall in temperature as the capsule fell into the toilet bowl. Patients returned the receiver after 4 days, and the data were downloaded to a computer.

\section{Analysis}

Data analysis was performed using the MotiliGI version 3.0.20 (Given Image, Yokneam Illit, Israel). The software presents a graph visualizing the $\mathrm{pH}$ and pressure, as well as the temperature throughout the GI tract. The physician is instructed to identify the following physiological landmarks according to predefined criteria: capsule ingestion, gastric emptying (GE), ICJ, and bowel exit. The software compares the physician identified markers to those identified by the computer. If not equivalent, the software allows users to choose between marks defined by the program or previously identified landmarks. The process provides 2 sets of markers: the physician confirmed and the computed. Based on these physiological landmarks the following values can be calculated: GE time, small bowel transit time, colonic transit time, whole gut transit time, and combined small and large bowel transit time. Furthermore, the software analyses the mean and maximum pressures as well as the contractions per minute through the segments.

\section{Identification of the lleocolic Junction}

\section{Computed ileocolic junction}

The software selects the ICJ by finding the first and largest $\mathrm{pH}$ drop between 30 minutes and 6 hours from GE.

Table 1. Independent Identification of the Ileocolic Junction by the Computer and the 2 Raters

\begin{tabular}{|c|c|c|c|c|c|}
\hline & & \multicolumn{3}{|c|}{$\mathrm{ICJ}(\mathrm{n})$} & \multirow{2}{*}{ Exams (n) } \\
\hline & & $\mathrm{PC}$ & Y.T. & D.I. & \\
\hline \multirow[t]{2}{*}{ Pre-operative } & $\mathrm{ICJ}^{\mathrm{a}}$ found: & 9 & 13 & 13 & 13 \\
\hline & $\mathrm{ICJ}^{\mathrm{b}}$ deviation: & 2 & 0 & 0 & \\
\hline \multirow[t]{2}{*}{3 wk after surgery } & $\mathrm{ICJ}^{\mathrm{a}}$ found: & 8 & 13 & 13 & 13 \\
\hline & $\mathrm{ICJ}^{\mathrm{b}}$ deviation: & 1 & 1 & 1 & \\
\hline \multirow[t]{2}{*}{6 mo after surgery } & $\mathrm{ICJ}^{\mathrm{a}}$ found: & 10 & 13 & 13 & 13 \\
\hline & $\mathrm{ICJ}^{\mathrm{b}}$ deviation: & 3 & 0 & 0 & \\
\hline \multirow[t]{2}{*}{ All exams } & $\mathrm{ICJ}^{\mathrm{a}}$ found: & 27 & 39 & 39 & 39 \\
\hline & $\mathrm{ICJ}^{\mathrm{b}}$ deviation: & 6 & 1 & 1 & \\
\hline
\end{tabular}

${ }^{a}$ Ileocolic junction (ICJ) found by: the computer (PC), Y.T., and D.I.

${ }^{\mathrm{b}} \mathrm{ICJ}$ deviating more than 10 minutes from the other 2 raters.

Exams, examinations.

\section{Physician-confirmed ileocolic junction}

Physician-confirmed ICJ is based on the validated stereotypical changes in the $\mathrm{pH}$ profile through the GI tract. An abrupt sustained rise in $\mathrm{pH}$ of more than two units delineates the GE. After the GE, a steady rise in the $\mathrm{pH}$ followed by a plateau represents the passage through the small bowel. A drop of $0.5-2.0 \mathrm{pH}$ units usually occurs when the capsule enters the colon (due to bacterial fermentation), ${ }^{11}$ thereby defining the ICJ. After the ICJ an erratic $\mathrm{pH}$ profile in the colon is characteristic. Inter-rater reliability was assessed for 2 of the authors (Y.T. and D.I.) independently from each other, and the computer for identification of the ICJ (minutes elapsed from activation of the capsule) on all graphs. The authors were blinded for the bowel length removed, operation, and examination.

The data on magnitude and duration of the $\mathrm{pH}$ drop within the ICJ were drawn from the graph produced by the software.

\section{Pressure Prior to the lleocolic Junction}

In the Statistics mode in MotiliGI a window over the last 4 minutes prior to the ICJ was selected. MotiliGI generates a report for the selected window, including the highest pressure.

\section{Histology}

Data on the lengths of formol-fixed bowel resected were drawn from the histopathology report. Due to shrinkage the fixed specimen is shorter than the natural length. ${ }^{12}$

\section{Statistical Methods}

To determine the inter-rater reliability the intra-class correlation coefficient (ICC) was calculated using the R-package psych. Paired-Samples T-Test in SPSS version 22 (IBM Corp, Armonk, NY, USA) was used to estimate the change in magnitude and duration of the $\mathrm{pH}$ fall. The same test was used to compare the pressure prior to ICJ before and after surgery.

Table 2. Correlation Between the Ileocolic Junctions Found by the 2 Raters

\begin{tabular}{lcc}
\hline & $\begin{array}{c}\text { ICC } \\
\text { (Y.T.-D.I. })\end{array}$ & $\begin{array}{c}\text { Mean difference } \\
(\mathrm{min})\end{array}$ \\
\hline Pre-operative & 0.99 & 1.58 \\
3 wk after surgery & 0.91 & 6.30 \\
6 mo after surgery & 0.99 & -0.33 \\
\hline
\end{tabular}

ICC, intra class correlation. 

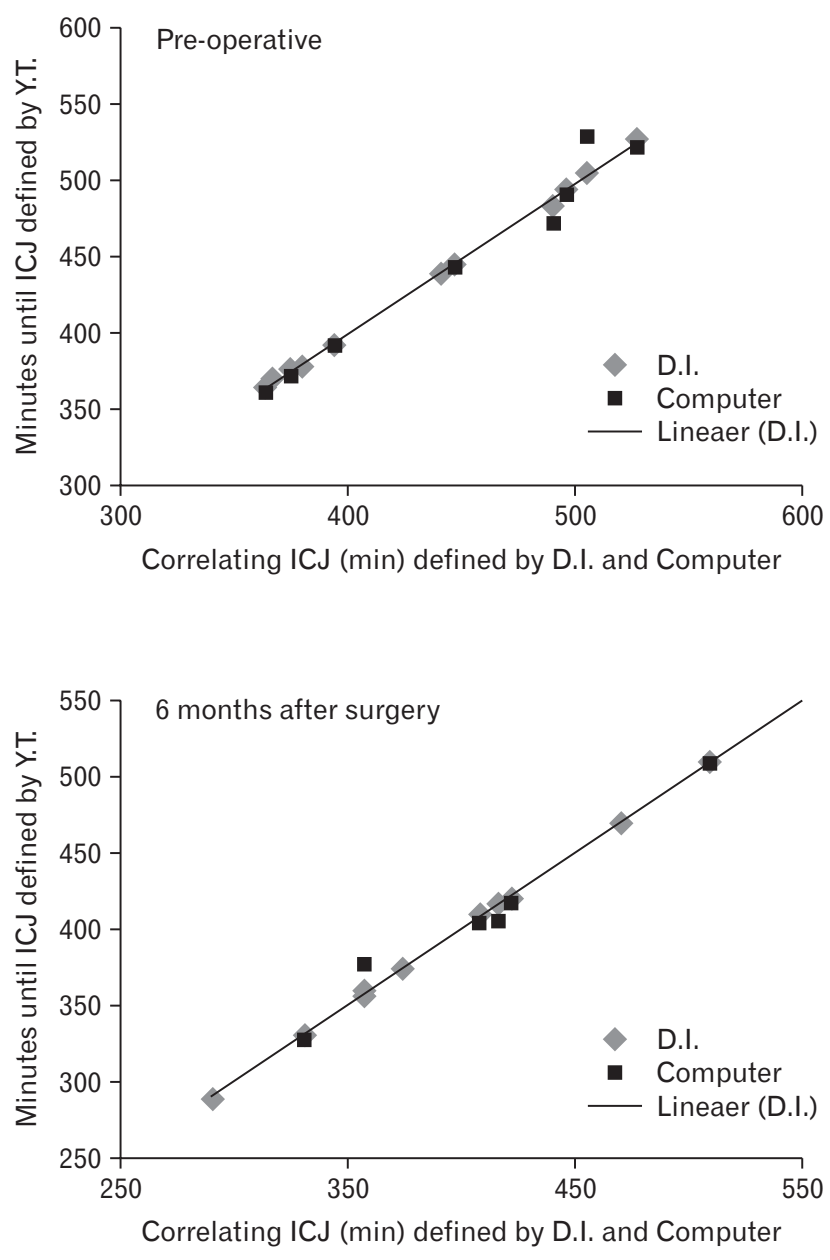

\section{Results}

Between July 2013 and December 2015 a total of 20 patients ( 8 men) were included in the study, 7 (4 men) were excluded: 4 due to poor recordings (major breaks around the expected location of the ICJ in 1 or more of the 3 recordings), 2 due to unforeseen surgical events, and 1 patient could not swallow the second WMC. Thirteen patients ( 4 men) with a median age of 63 years successfully completed all 3 tests. Median bowel lengths removed by the procedure were 11 (4-20) $\mathrm{cm}$ for the terminal ileum and 21 (14-34) $\mathrm{cm}$ for the colon. All 39 examinations were analyzed to identify the ICJ. The physicians found all ICJs before and after surgery while the computer did not; the results and equivalence between the raters are presented in Table 1.

The inter-rater reliability between the 2 physicians was very high with only a mean difference of 0.33 minutes after 6 months (Table 2).

Figure 1 graphically depicts the correlation between the ICJ

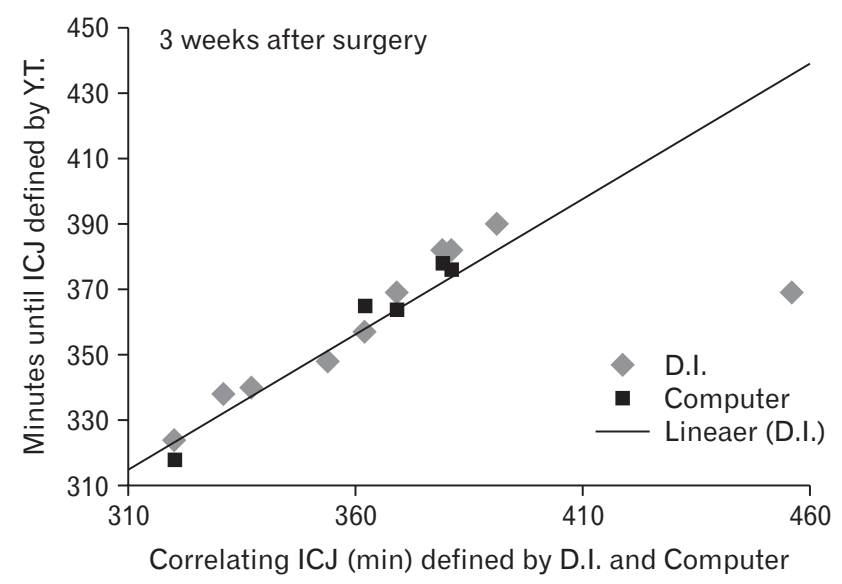

Figure 1. Time (minutes) from pill activation to the ileocolic junction (ICJ) determined by Y.T. (x-axis) and the corresponding values determined by D.I. and the computer (y-axis). In both the first and the last graph one outlier (due to gastroparesis) with a very long time from activation to ICJ was excluded from the graph (but not from the results).

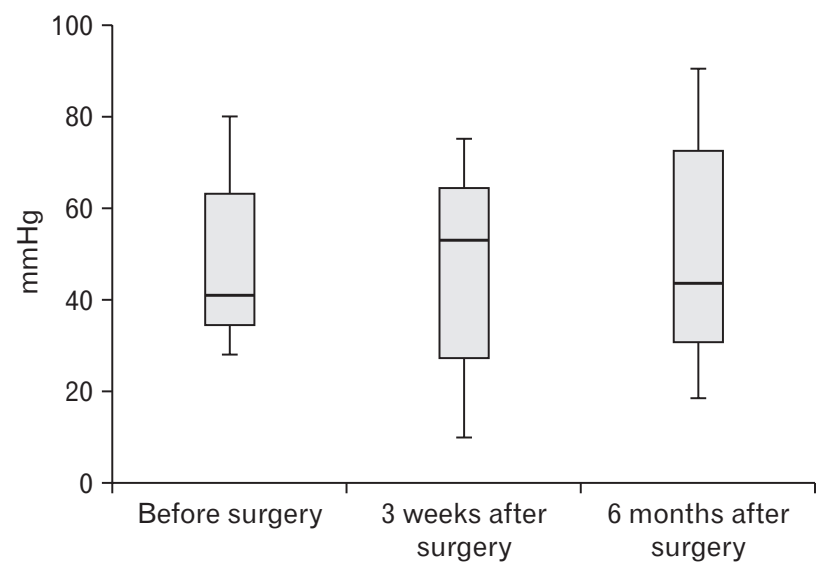

Figure 2. Boxplot presenting the highest pressure $(\mathrm{mmHg})$ over a 4-minute window prior to the characteristic $\mathrm{pH}$-drop at the ileocolic junction. 
defined by Y.T., D.I., and the computer for each test.

The magnitude and duration of the $\mathrm{pH}$ drop for the 3 examinations shows a tendency toward longer times and smaller falls 3 weeks after surgery. Compared to the mean duration (3.15 minutes) before surgery, the duration 3 weeks and 6 months after surgery were 1.63 minutes $(P=0.358)$ and 0.60 minutes $(P=0.584)$ longer, respectively. Compared to the pre-operative mean $\mathrm{pH}$ drop (1.16 $\mathrm{pH}$ units), the $\mathrm{pH}$ drop 3 weeks and 6 months after surgery were $0.14 \mathrm{pH}$ units $(P=0.387)$ and $0.03 \mathrm{pH}$ units $(P=0.683)$ smaller, respectively.

The highest pressure during a 4-minute window prior to the ICJ did not change significantly after the surgery. Compared to the pre-operative pressure the mean pressure 3 weeks after surgery was $1.19 \mathrm{mmHg}$ lower $(-22.13,19.75) P=0.901$, and the mean pressure 6 months after surgery was $0.62 \mathrm{mmHg}$ higher $(-18.31$, 19.54) $P=0.943$ (Fig. 2).

After the initial post-operative phase none of the patients had diarrhea. Figure 3 displays a comparison of the 3 consecutive tests
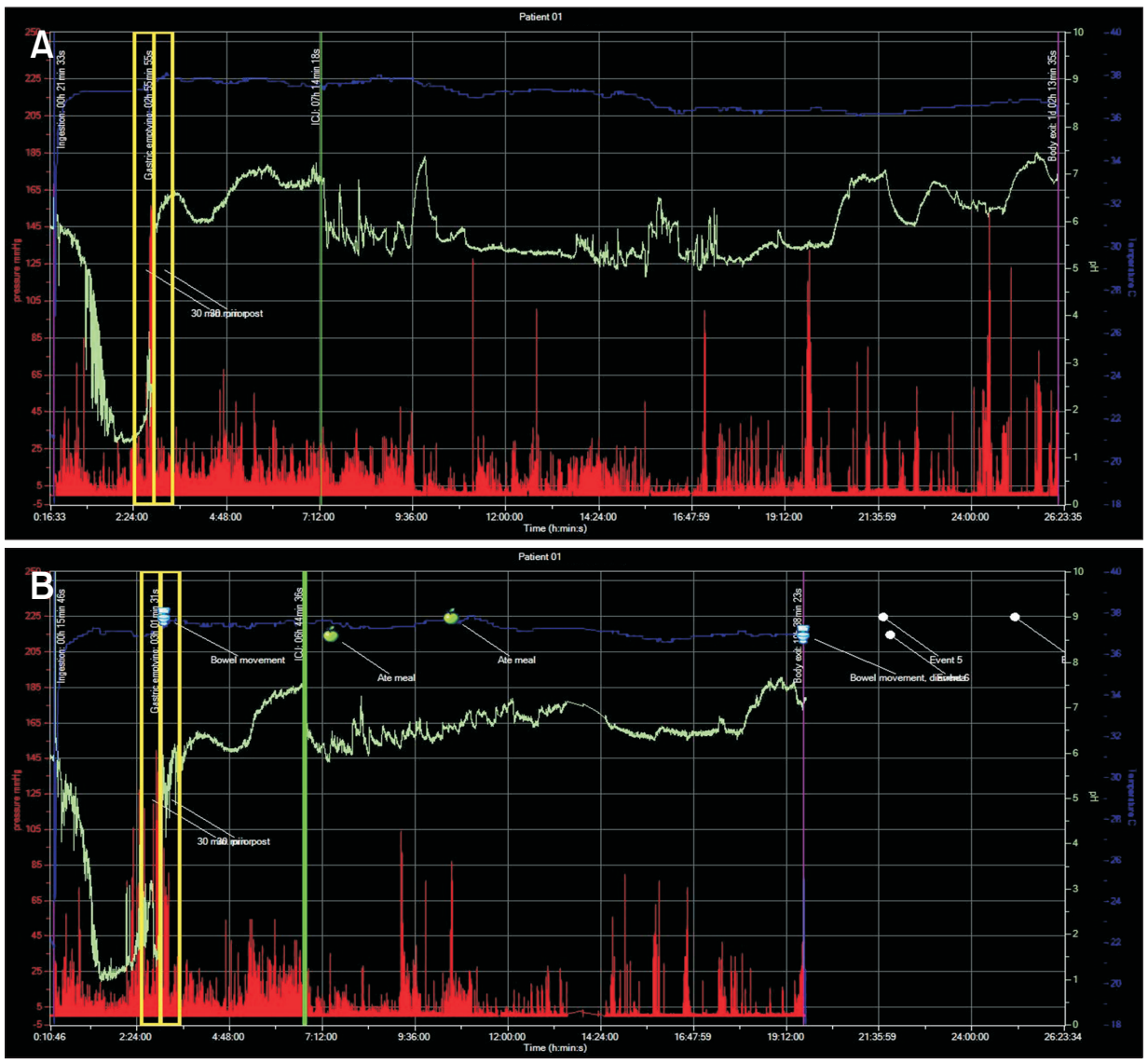

Figure 3. The 3 consecutive examinations in 1 patient. (A) The pre-operative test demonstrating the stereotypical pattern. After gastric emptying, the $\mathrm{pH}$ rises abruptly for at least $2 \mathrm{pH}$-units and continues to climb until it reaches a plateau. At the end of the plateau, a

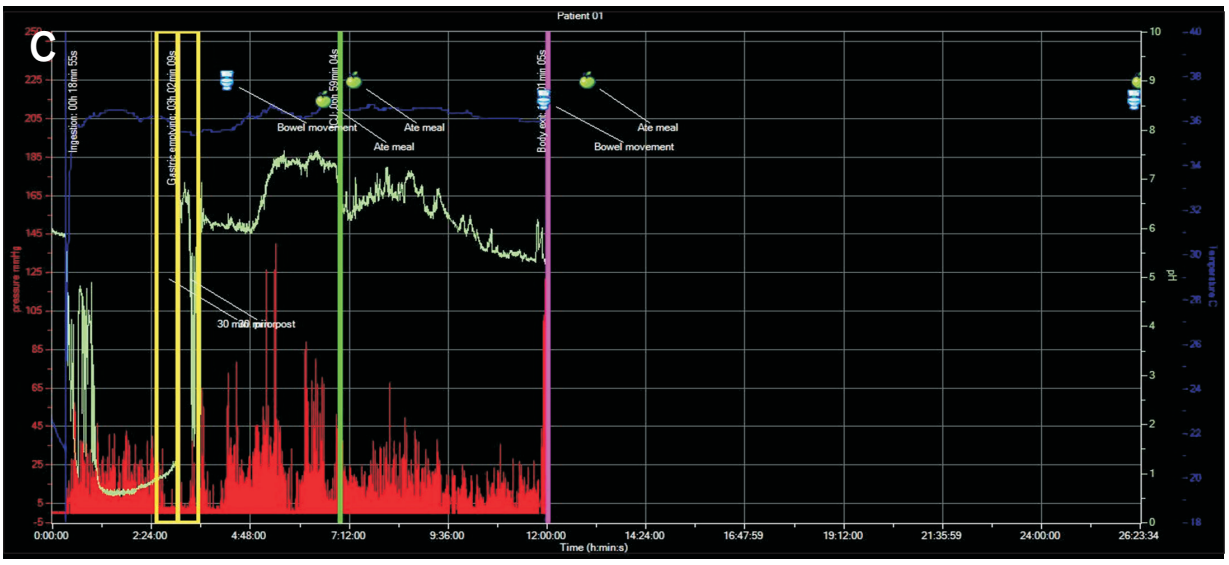
sudden $\mathrm{pH}$-fall occurs when the capsule passes over from the ileum into the colon. After the ileocolic junction, we see an irregular $\mathrm{pH}$-pattern, which is very typical for the colon. (B) Three weeks after surgery the same characteristic pattern is present. In this patient, the $\mathrm{pH}$ drop is little affected. The colon transit time is reduced by about one-third. The small bowel transit time is only slightly reduced. (C) Six months after surgery the small bowel transit time is normalized. The $\mathrm{pH}$ drop is still clearly visible and the colon transit time is reduced. 
with the WMC in 1 patient.

\section{Discussion}

This article documents the ability of the WMC to identify the surgically created (non-physiological) ICJ after a right colectomy. However, as already described by Wang et al. the automatic identification of the ICJ by the computer seems to be too simplified and therefore often fails to recognize the ICJ. ${ }^{10}$ The number of ICJs identified by the computer is not higher prior to surgery than it is 6 months after, indicating that this is independent of the procedure. The physician confirmed values, though, based on the stereotypical changes in the $\mathrm{pH}$-profile seem to be much more reliable. Even after surgery, we find the same curve with the same $\mathrm{pH}$-fall around the ileocolic region that Zarate et $\mathrm{al}^{11}$ described in their validation of the WMC. This is clearly visible in Figure 3. In our study, the inter-rater reliability between the 2 independent physicians is very high, expressed by an ICC of 0.99 both before and 6 months after surgery. However, 3 weeks after surgery the stereotypical $\mathrm{pH}$ profile (the graph displayed by the software) often is somewhat disturbed, making the identification of the ICJ more difficult. The duration of the $\mathrm{pH}$-drop appears to be longer, and the magnitude smaller. Even though the differences were too small to be significant in our small sample, the trend is clear. The delicate mechanism of the ICJ seems to be disrupted leading to longer times for chyme transit through the non-physiological and surgically created ICJ, and in addition possible regurgitation. Nonetheless, the ICC between the physicians on the examination 3 weeks after the operation was still relatively high (0.91). The 6 month curve indicates similar function as before surgery implicating a possible compensatory mechanism that is not valve related.

It is known that up to $15 \%$ of subjects fail to show a characteristic sharp fall in $\mathrm{pH}$ at the ICJ. ${ }^{11}$ Zarate et al ${ }^{11}$ wondered if this is related to ileocolic valve competence. Roland et $\mathrm{al}^{6}$ found an association between a low pressure prior to the ICJ and small intestinal bacterial overgrowth. They suggested that a low pressure indicates lack of valve competence. These changes concerning the characteristic $\mathrm{pH}$ drop or the pressure prior to the ICJ when the ileocecal valve is surgically removed are not confirmed in our study. Our present data indicate that the valve competence cannot be assessed using the $\mathrm{WMC}$. The slightly altered $\mathrm{pH}$-profile in the early postoperative period might also be related to a disturbance of the bacterial colonization in the colon and possibly also to bacterial growth in the small intestine due to stagnation of the chyme in the first days after the operation.
Some authors emphasize that the anatomy and physiology of the most terminal part of the ileum differ from the rest, rendering it a sphincter. ${ }^{13}$ One can question if the "neoterminal" ileum created after surgery is functionally comparable to the physiological terminal ileum. Nevertheless, the limited small bowel resection (median length $11 \mathrm{~cm}$ ) diminishes the importance of this question. One could also argue that the extended D3 mesenterectomy (which entails a more extensive mesenterectomy than at standard surgery ${ }^{7,8}$ ) could affect the contractility. The lack of a significant change in mean and high pressure in the small bowel 6 months after surgery makes this explanation unlikely.

The strength of this study is in the prospective data collection and the fact that every patient represents his own control, such a paired design excludes personal variation, in this way providing a firm groundwork for the conclusions drawn. A potential weakness is the low number of patients, as well as the fact that one-third of the patients were excluded from the analysis.

In conclusion, the WMC can identify the ICJ after a right colectomy. The accuracy is, however, somewhat reduced in the initial post-operative phase, due to a slightly disturbed $\mathrm{pH}$-profile. ICJ valve competence cannot be assessed through the WMC.

Financial support: Funding for the research and the publication came from the Vestfold Hospital Trust (Grant No. B-2013/FoU$05)$.

\section{Conflicts of interest: None.}

Author contributions: Yngve Thorsen, Dejan Ignjatovic, and Bojan V Stimec, designed the study; the data collection was performed by Yngve Thorsen and Jens M Nesgaard; the data were analyzed by Yngve Thorsen and Dejan Ignjatovic and interpreted by the group; the article was written by Yngve Thorsen and Dejan Ignjatovic; and Jens M Nesgaard and Bojan V Stimec contributed in writing parts of the manuscript and revising it.

\section{References}

1. Rao SS, Camilleri M, Hasler WL, et al. Evaluation of gastrointestinal transit in clinical practice: position paper of the American and European Neurogastroenterology and Motility Societies. Neurogastroenterol Motil 2011;23:8-23.

2. Tran K, Brun R, Kuo B. Evaluation of regional and whole gut motility using the wireless motility capsule: relevance in clinical practice. Therap Adv Gastroenterol 2012;5:249-260.

3. Maqbool S, Parkman HP, Friedenberg FK. Wireless capsule motility: 
comparison of the SmartPill GI monitoring system with scintigraphy for measuring whole gut transit. Dig Dis Sci 2009;54:2167-2174.

4. Lee YY, Erdogan A, Rao SS. How to assess regional and whole gut transit time with wireless motility capsule. J Neurogastroenterol Motil 2014:20:265-270.

5. Arora Z, Parungao JM, Lopez R, Heinlein C, Santisi J, Birgisson S. Clinical utility of wireless motility capsule in patients with suspected multiregional gastrointestinal dysmotility. Dig Dis Sci 2015;60:1350-1357.

6. Roland BC, Ciarleglio MM, Clarke JO, et al. Low ileocecal valve pressure is significantly associated with small intestinal bacterial overgrowth (SIBO). Dig Dis Sci 2014;59:1269-1277.

7. Nesgaard JM, Stimec BV, Bakka AO, Edwin B, Ignjatovic D; RCC study group. Navigating the mesentery. A comparative pre- and per-operative visualization of the vascular anatomy. Colorectal Dis 2015;17:810818.

8. Thorsen Y, Stimec B, Andersen SN, et al. Bowel function and quality of life after superior mesenteric nerve plexus transection in right colectomy with D3 extended mesenterectomy. Tech Coloproctol 2016;20:445-453.

9. Saad RJ. The wireless motility capsule: a one-stop shop for the evaluation of GI motility disorders. Curr Gastroenterol Rep 2016;18:14.

10. Wang YT, Mohammed SD, Farmer AD, et al. Regional gastrointestinal transit and $\mathrm{pH}$ studied in 215 healthy volunteers using the wireless motility capsule: influence of age, gender, study country and testing protocol. Aliment Pharmacol Ther 2015;42:761-772.

11. Zarate N, Mohammed SD, O'Shaughnessy E, et al. Accurate localization of a fall in $\mathrm{pH}$ within the ileocecal region: validation using a dualscintigraphic technique. Am J Physiol Gastrointest Liver Physiol 2010;299:G1276-G1286.

12. Chen CH, Hsu MY, Jiang RS, Wu SH, Chen FJ, Liu SA. Shrinkage of head and neck cancer specimens after formalin fixation. J Chin Med Assoc 2012;75:109-113.

13. Malbert CH. The ileocolonic sphincter. Neurogastroenterol Motil 2005;17(suppl 1):41-49. 